\title{
The Effect of Perceived Environmental \\ Uncertainty on the Use and Perceived \\ Usefulness of Strategic Management \\ Accounting: Some Empirical Evidence
}

\author{
Antonio Costantini \\ University of Udine, Italy \\ antonio.costantini@uniud.it
}

Filippo Zanin

University of Udine, Italy

filippo.zanin@uniud.it

The purpose of this paper is to investigate whether perceived environmental uncertainty (PEU) affects the use and the perceived usefulness of strategic management accounting (SMA). The study takes the perspective that SMA can be regarded as a set of strategically oriented management accounting techniques and makes the research hypothesis that as PEU increases the use and perceived usefulness of s M A techniques also increase. To test the hypothesis, the responses of $55 \mathrm{CFO}$ to a questionnaire survey were analysed. The survey considered a cross-section of large manufacturing companies in Italy. The regression-based analysis mainly shows: (1) a positive relationship between PEU and the use of strategic pricing as SMA technique supporting product pricing decisions; (2) a positive relationship between PEU and the use of balanced scorecard; (3) a positive association between PEU and the perceived usefulness of all the SMA techniques included in the study.

Key Words: management control, perceived environmental uncertainty, strategic management accounting

JEL Classification: M 41

https://doi.org/10.26493/1854-6935.15.379-398

\section{Introduction}

In accounting literature there is general consensus that perceived environmental uncertainty ( $\mathrm{PEU}$ ) is a fundamental contingency variable affecting management control systems design and use. In particular, PEU has been associated with the use and usefulness of broad scope management accounting (Chenhall 2003). The present study aims to investigate the relationship between PEU and strategic management account- 
ing (SMA) as specific broad scope management accounting. sMA entails the preparation and provision of information to support the strategic decisions in organizations (Bhimani 2013). Information is needed at each stage of the strategic decision-making process (Invernizzi 2005), and, further, strategic decisions are affected by the managerial perceptions of the uncertainty related to the external environment (Tymon, Stout, and Shaw 1998).

The study takes the perspective that SMA can be viewed as a set of strategically oriented accounting techniques (Cadez and Guilding 2008) and considers various SMA techniques drawn from previous studies (Cinquini and Tenucci 2010). Traditional management accounting, which is mostly short-term, internally oriented, based on past financial results, and dealing with regular events, is inadequate for strategic decision-making. In contrast, sM A techniques exhibit environmental (outward-looking), and/or long-term (forward-looking) orientation (Guilding, Cravens, and Tayles 200o). sm A techniques may involve collection of information about competitors, taking advantage of cost reduction opportunities through value chain and cost drivers analysis, performance measurement systems that help translate strategy into objectives and measures (Lord 2007).

Despite there are a number of studies investigating the incidence and perceived merit of SMA practices in many Countries, further research is needed to explore the potential determinants of sma adoption, and the development of a sound contingency framework for SMA is still in its initial stage (Cadez and Guilding 2008; Noordin et al. 2015).

This provides the motivation for this exploratory research, which makes the hypothesis that as PEU increases the use and perceived usefulness of sMA techniques increase to support more informed and accurate strategic decisions. As such, a congruence approach is followed as form of contingency fit, as the relationship between PEU and SMA techniques is analysed with no regard to firm performance (Gerdin and Greve 2004).

The study reports the findings of a questionnaire survey based on a sample of 55 large manufacturing firms from Italy. Based on prior literature (e.g. Gordon and Narayanan 1984), PEU is measured using the respondents' perceptions about predictability and pressures of different environmental aspects. Moreover, respondents were asked whether they use sma techniques and to indicate their usefulness for strategic decisionmaking.

The study seeks to make two connected contributions. First, it updates 
previous results on the use and perceived usefulness of a set of management accounting techniques that are non-conventional and relatively recently conceived. Secondly, drawing on quantitative empirical data and focusing on $\mathrm{PEU}$ as contingent variable, it extends contingency-based hypotheses regarding sMA to increase knowledge on the antecedents of its use.

\section{Literature Review}

\section{PERCEIVED ENVIRONMENTAL UNCERTAINTY}

AND MANAGEMENT ACCOUNTING

Environmental uncertainty is a fundamental concern that managers have to consider in the strategic decision process, with the purpose of adapting the organization's activities to the environmental opportunities (Milliken 1987). Environmental uncertainty is generally referred to the changing conditions of the environment and their unfolding in an unpredictable way. It is driven by factors such as technological changes in manufacturing and operations, process innovations, actions of competitors, customers' needs and preferences, relations with suppliers, market demand, macroeconomic and industry trends, government policies, and deregulation and globalization issues (Hoque 2005).

Different authors have argued that the perceptions of environmental uncertainty, rather than actual uncertainty, influence managerial decision-making (Gul and Chia 1994). PEU refers to managers' inability to accurately predict the external environment of the organization (Tymon, Stout, and Shaw 1998). In particular, Milliken (1987) describes three types of PEU. The first is state uncertainty, generally meaning that managers are not able to predict how factors of the environment might be changing. Secondly, effect uncertainty refers to the inability to predict the impact of environmental events or changes on the organization. Third, response uncertainty is depicted as the inability to predict the likely consequences of a response to the events. Hence, PEU results in a lack of information about external environment that affects strategic decisions.

Generally, PEU makes managerial planning and control more difficult (Chenhall and Morris 1986). Uncertainty impacts on strategic planning, budgeting and performance evaluation processes, as in unstable and changing environments it is more difficult to attain reliable financial and market forecasts and ex-ante target setting due to unpredictability of future events. In addition, PEU affects organizational structure, whose 
design should enable to respond more effectively to the environmental demands, also through more open and externally focused management control systems (Chenhall 2003).

However, PEU can nevertheless be reduced by the attainment of more information, which can alleviate the difficulties in planning and control (Chenhall and Morris 1986). With this purpose, the information processing capabilities of firms should be consistent with the uncertainty perceived in the environment. Many accounting studies have explored the relationship between PEU and management accounting following a contingency approach (Otley 2016). Specifically, PEU, as contextual variable, has been associated with the use and usefulness of broad scope management accounting. Broad scope management accounting, as opposed to narrow scope, generally provide information regarding internal and external environment, is historical and future-oriented, quantitative and qualitative, and includes financial and non-financial measures (Chong and Chong 1997).

Different contingency-based researches suggested that under conditions of high PEU, the use of sophisticated broad scope reports could reduce uncertainty and support more informed managerial decisionmaking. For example, Gordon and Narayanan (1984) showed that increased PEU is positively associated with the perceived importance of external, non-financial and ex-ante information. Gul and Chia (1994) found a significant positive relationship between the use of broad scope management accounting information and higher performance under conditions of high PEU, and Agbejule (2005) also showed that the higher the level of PEU, the more broad scope management accounting is beneficial to performance.

\section{STRATEGIC MANAGEMENT ACCOUNTING: AN OVERVIEW}

Management accounting involves providing information to managers, and management accounting practices are developed to satisfy the information needs for planning and control purposes (Noreen, Brewer, and Garrison 2011). This could incorporate an array of information needs from operational to strategic (Pitcher 2015). However, traditional (conventional) management accounting collects data and evidence to compose timely reports that inform management decisions at the operational level. Further, traditional management accounting practices, such as budgets, variance analysis, cost accounting, and performance measures such as ROI, mainly focus on routine and internal concerns and 
have short-term financial orientation (Chenhall and Langfield-Smith 1998).

Because of the primary focus on internal aspects (inward-looking) and on past results (backward-looking), Lord (2007) claims that the use of traditional management accounting for strategic decision-making raises problems. In fact, strategic decisions are usually long-term, involve several internal and external variables, are non-routine and made under uncertainty about the future.

In this light, sMA is a form of management accounting entailing the preparation and presentation of information for strategic decision-making, placing special emphasis on external (environmental) factors and forward-looking (future-oriented) concerns (Bhimani 2013). sM A can be viewed as broad scope management accounting and deviates from traditional (conventional) management accounting in many characteristics, which literature has discussed (Coad 1996; Lord 2007).

Despite several authors have noted that the boundaries of SMA are still unclear (Carlsson-Wall, Kraus, and Lind 2015), sm A serves the purpose of performing a range of activities revolving around strategic decisionmaking, such as environmental analysis, strategic alternatives generation and selection, strategic plan implementation and the consequent controls (Brouthers and Roozen 1999). Generally, in increasingly dynamic environments the provision of strategically relevant information can be fundamental to the key stages of the strategic management process (Nixon and Burns 2012).

In SMA literature three major strands can be identified (LangfieldSmith 2008). A first body of literature comprises conceptual models for SM A, for example Simmonds (1981), Bromwich (1990), Shank and Govindarajan (1993), and Ward (1992).

A second research strand has generated insights through theoretically grounded case studies, such as Lord (1996), Roslender and Hart (2003), Tillmann and Goddard (2008), and Carlsson-Wall, Kraus, and Lind (2015).

A third strand includes surveys of practice addressing sm a adoption and implementation. Survey-based studies have especially investigated the use and the perceptions of SMA techniques merit, describing the state of the art in individual countries (Guilding and McManus 2002; Noordin, Zainuddin, and Tayles 2009) or through cross-country comparisons (Guilding, Cravens, and Tayles 2000; Cadez and Guilding 2007). Some surveys have also concentrated on the relationship between strat- 
egy and SM A (Bhimani and Langfield-Smith 2007; Cinquini and Tenucci 2010; Cescon, Costantini, and Grassetti 2016), with mixed results. Further, Cadez and Guilding (2008) have proposed a contingency framework for SMA, showing that the use of SMA techniques can be affected by different factors (various strategy-related facets and company size), and that SMA, in turn, has a beneficial mediating effect on firm performance.

This study adds to the strand of survey-based research, introducing PEU as a factor that may affect SMA use. In particular, it follows a congruence approach as it assumes a relationship between PEU (as contextual variable) and sma (as structure variable) without investigating whether this relationship influences performance (Gerdin and Greve 2004).

Further, as highlighted by Cadez and Guilding (2008), literature suggests that two perspectives on SMA may be taken. First, SMA can be conceived as a set of accounting techniques allowing the collection and analysis of information for strategic decision-making. Secondly, sMA is concerned with the participation of accountants in strategic decision-making processes. The present study takes the former perspective and, in particular, considers ten SMA techniques: life cycle costing, quality costing, target costing, value chain costing, strategic pricing, competitor position monitoring, competitor cost assessment, competitor appraisal based on published financial statements, brand valuation, and balanced scorecard. They are mainly drawn from Guilding, Cravens, and Tayles (2000) and Cinquini and Tenucci (2010), who provided an exhaustive explanation of each technique.

\section{Development of Hypotheses}

Brouthers and Roozen (1999) developed and presented a SMA framework in which different information requirements were derived for different levels of environmental uncertainty. For example, they emphasized that in repetitive and stable environment the content of information should be mostly internal and quantitative, with an historic focus, while in changing environments, characterized by higher levels of uncertainty, strategic decision-making and planning implementation should be assisted by the provision of information that is internal and external, quantitative and qualitative, focused on present and future.

Gul (1991) suggest that when PEU is high, managers would need nontraditional and more advanced management accounting information (such as economic and non-economic information external to the firm), to cope with the uncertainty and make decisions that are more appro- 
priate. Cescon (2010) found that firms perceiving high PEU tend to use innovative costing techniques, such as target costing and life cycle costing, for strategic purposes. Chong and Chong (1997) examined the role of management accounting on the linkages between strategy and PEU on strategic business unit ( $\mathrm{SBU}$ ) performance and argued that firms perceiving more environmental uncertainty put greater reliance on using external, non-financial and future-oriented information. These studies appear to draw attention to a positive association between accounting information usage and PEU. According to the main objective of this study, it is also important to recognize the SMA's role in providing managers with incremental information not generated by a conventional accounting information system (Kalkhouran et al. 2015). These aspects can be summarized with the following hypothesis:

H1A PEU and the use of SMA techniques are positively associated.

As regards the possible association between PEU and the perceived usefulness of sma techniques, two researches are particularly significant as they address the relationship between PEU and the perceived usefulness of strategically oriented management accounting techniques. Gordon and Narayanan (1984) found that as PEU increases, managers consider external, non-financial and ex-ante (forward-looking) information to be increasingly important. In a similar vein, Chenhall and Morris (1986) emphasized that PEU positively influences the extent to which managers perceive broad scope information as useful. As noted by Fisher (1995), the ultimate goal of management accounting system should be to support the decision-making process by providing top managers with a comprehensive information set that includes both conventional and strategically oriented accounting information. Furthermore, Lal and Hassel (1998) find that the usefulness of strategy driven management accounting could be even better explained when the interactions between PEU and cognitive style of top managers are considered. A sound balance between the conventional and strategically oriented uses of accounting information is fundamental to cope with a wide range of contingency variables and therefore sMA techniques appears of primary importance for the successful management of PEU. Consistent with this movement from traditional accounting information to a more multidimensional information system, the following hypothesis can be proposed:

H1 B PEU and the perceived usefulness of SMA techniques are positively associated. 


\section{Research Method}

SAMPLE

The data used in this study were collected through a questionnaire-based survey. An initial sample comprised 223 large manufacturing firms (with annual sales exceeding 100 million Euros). Firms were randomly chosen from the dataset provided by the Italian Chambers of Commerce (CCIA A). In a first stage of the survey, letters were sent to the Chief Executive Officers of the 223 firms to illustrate the research topics and objectives and invite to participate. Overall, 74 companies accepted to respond to the questionnaire. In a second stage, these 74 firms were sent an e-mail containing a link to access the web questionnaire and general instructions. Fifty-five complete and usable questionnaires were received, which represents a response rate of $24.7 \%$. The respondents were mainly Chief Financial Officers (CFOS).

To investigate for possible non-response bias, a Chi-Square test was carried out to detect for potential differences in the industrial sector distribution between firms that completed the questionnaire and those that did not respond. No significant differences were found $(p=0.63)$, suggesting the absence of biases.

\section{VARIABLES MEASUREMENT \\ Perceived Environmental Uncertainty}

PEU was measured using eight items adapted from Gordon and Narayanan (1984) and Hoque (2005). Respondents were asked to indicate their perception, on a seven-point Likert scale ranging from 1 (very low) to 7 (very high), about the uncertainty regarding various aspects of their firm's environment (table 1).

The reliability of the scale was measured by determining the Cronbach alpha coefficient (Cronbach 1951). This was equal to 0.69 , indicating moderate internal consistency of the items that can be accepted for exploratory research (Robinson, Shaver, and Wrightsman 1991; Hair et al. 2010).

This result enables the calculation of a total score of the perceived uncertainty for each firm (Sullivan and Artino 2013). Following Lal and Hassel (1998), total score was calculated as the sum of the item scores and it is used as independent variable in the regression analyses to test the hypotheses.

Table 1 provides descriptive statistics of the environmental uncertainty 
TABLE 1 Descriptive Statistics of the Environmental Uncertainty Items

\begin{tabular}{lrrrr}
\hline Item & $(1)$ & $(2)$ & $(3)$ & $(4)$ \\
\hline Change in the macroeconomy and in the sector & 5.64 & 1.17 & 6 & $5-7$ \\
Competitors' actions & 5.13 & 1.40 & 5 & $5-6$ \\
Introduction of new products by competitors & 4.93 & 1.41 & 5 & $4-6$ \\
Consumer demands and preferences & 4.67 & 1.35 & 5 & $4-6$ \\
Manufacturing technologies & 4.55 & 1.78 & 5 & $3-6$ \\
Change in the customers power & 4.40 & 1.38 & 4 & $4-5$ \\
Government regulation and policies & 4.18 & 1.67 & 4 & $3-5$ \\
Suppliers' actions & 3.53 & 1.17 & 3 & $3-4$ \\
\hline
\end{tabular}

Notes Column headings are as follows: (1) mean, (2) standard deviation, (3) median, (4) IQR.

items. The table includes central tendency measures of the degree of perceived uncertainty for each item, such as mean and median, and variability measures, such as standard deviation and interquartile range (IQR). The items are presented in decreasing order based on mean perceived uncertainty.

\section{Use and Usefulness of Strategic Management Accounting Techniques}

The survey requested firms to indicate whether they use sma techniques to support the strategic decision process. The techniques were selected based on previous studies (Guilding, Cravens, and Tayles 2000; Cinquini and Tenucci 2010), as outlined in the overview of SMA, and itemized in the questionnaire. A brief description of the techniques was included in a glossary delivered with the questionnaire to help a homogeneous understanding.

For data analysis purposes, the use of each SmA technique is represented through a binary variable $(Y)$ where a value of 1 was attached to firms that declared using SMA techniques ('users') and a value of o to firms that did not ('non-users').

Then, following the same approach of prior studies (Guilding, Cravens, and Tayles 2000) firms were asked to indicate the perceived usefulness of each SMA technique on a seven-point Likert scale ranging from 1 (very low) to 7 (crucial). For data analysis purposes, the perceived usefulness of SMA techniques is represented through a variable measured on an ordinal level assuming values from 1 to 7 . The study employs logistic regression to investigate the hypothesized relationships. 
TABLE 2 SMA Techniques Usage Rates

\begin{tabular}{llrr}
\hline sM A techniques & Users & $\%$ \\
\hline 1 Competitor position monitoring & 45 & 81.8 \\
2 & Balanced scorecard & 37 & 67.3 \\
3 & Brand valuation & 35 & 63.6 \\
4 & Strategic pricing & 32 & 58.2 \\
5 & Competitor appraisal based on published financial statements & 28 & 50.9 \\
6 & Target costing & 27 & 49.1 \\
7 & Competitor cost assessment & 20 & 36.4 \\
8 & Value chain costing & 19 & 34.5 \\
9 Quality costing & 18 & 32.7 \\
10 Life cycle costing & 14 & 25.4 \\
\hline NOTES $n=55$. & &
\end{tabular}

\section{Analysis and Results}

Table 2 displays the counts of firms using the different sma techniques and the usage rates (in percentage). The techniques are presented in decreasing order according to usage rates, and ranks are reported in the first column. These results are quite consistent with previous studies (Guilding, Cravens, and Tayles 2000; Cinquini and Tenucci 2010) as regards the widespread use of competitor position monitoring and the lower use of costing techniques. Further, a high use of balanced scorecard is found. This differs from the results of Cadez and Guilding (2007) focused on Slovenia and Australia, where the use of balanced scorecard ranges from moderate to low, and those of Cinquini and Tenucci (2010), which reveal a low degree of use of integrated performance measurement systems across a sample of Italian manufacturing firms.

Table 3 exhibits an overview of the descriptive statistics regarding the degree of perceived usefulness for each SMA technique. Both measures of central tendency, such as mean and median, and measures of variability, such as standard deviation and IQR, are reported.

Again, the techniques are presented in decreasing order based on mean perceived usefulness, and ranks are reported in the first column.

All the SMA techniques present mean and median perceived usefulness greater than the central point of the scale. The degree of perceived usefulness is higher in particular for strategic pricing, competitor position monitoring, balanced scorecard, and value chain costing. Generally, while rates of use for a number of the considered techniques are rela- 
table 3 Descriptive Statistics of the Perceived Usefulness for Each sma Technique

\begin{tabular}{|c|c|c|c|c|}
\hline sma techniques & (1) & $(2)$ & (3) & (4) \\
\hline 1 Strategic pricing & 5.73 & 1.34 & 6 & $5-7$ \\
\hline 2 Competitor position monitoring & 5.56 & 1.62 & 6 & $5-7$ \\
\hline 3 Balanced scorecard & 5.35 & 1.54 & 6 & $5-7$ \\
\hline 4 Value chain costing & 5.04 & 1.46 & 5 & $4-6$ \\
\hline 5 Target costing & 4.93 & 1.45 & 5 & $4-6$ \\
\hline 6 Brand valuation & 4.75 & 1.66 & 5 & $4-6$ \\
\hline $\begin{array}{l}7 \text { Competitor appraisal based on published } \\
\text { financial statements }\end{array}$ & 4.64 & 1.46 & 5 & $4-6$ \\
\hline 8 Quality costing & 4.60 & 1.54 & 5 & $4-6$ \\
\hline 9 Competitor cost assessment & 4.55 & 1.40 & 5 & $4-5$ \\
\hline 10 Life cycle costing & 4.29 & 1.83 & 5 & $2.5-6$ \\
\hline
\end{tabular}
(4) IQR.

tively low, the mean and median scores of perceived importance are high or relatively high for all sm A techniques. Analogous results were found in Guilding, Cravens, and Tayles (2000) and Tenucci, Cinquini, and Giannetti (2010).

THE RELATIONSHIP BETWEEN PERCEIVED ENVIRONMENTAL

UNCERTAINTY AND THE USE OF SMA TECHNIQUES

H1A was tested carrying out a logistic regression analysis for each SMA technique. Logistic regression for a binary response variable $Y$ and an explanatory variable $X$ is based on the following linear relationship (Agresti 2002):

$$
\operatorname{logit}[\pi(x)]=\log \frac{\pi(x)}{1-\pi(x)}=\alpha+\beta X,
$$

where $\pi(x)=P(Y=1 \mid X=x)$ is the probability of using a certain SMA technique $(Y)$ and is expressed as a function of environmental uncertainty $(X) . X$, which is the explanatory variable, is calculated as the total score of the environmental uncertainty items $(x)$. Finally, $\alpha$ is the constant of the model.

To support $\mathrm{H} 1 \mathrm{~A}$, the coefficient $\beta$ in the regression equation should be significantly positive. This would indicate that the probability to use a certain SMA technique increases as PEU increases.

The results of logistic regressions are shown in table 4 . 
TABLE 4 The Relationship between PEU and the Use of sma Techniques

\begin{tabular}{lrrr}
\hline sM A techniques & $(1)$ & $(2)$ & $(3)$ \\
\hline Life cycle costing & 0.080 & 1.546 & 0.122 \\
Quality costing & 0.038 & 0.833 & 0.405 \\
Target costing & -0.017 & -0.399 & 0.690 \\
Value chain costing & 0.037 & 0.821 & 0.412 \\
Strategic pricing & 0.136 & 2.460 & $0.014^{*}$ \\
Brand valuation & 0.005 & 0.104 & 0.918 \\
Competitor position monitoring & 0.072 & 1.248 & 0.212 \\
Competitor cost assessment & 0.052 & 1.151 & 0.250 \\
Competitor appraisal based on published & -0.026 & -0.609 & 0.542 \\
financial statements & & & \\
Balanced scorecard & 0.115 & 2.136 & $0.033^{*}$ \\
\hline
\end{tabular}

Notes Column headings are as follows: (1) coefficient $(\beta),(2) t$ statistic, (3) $p$-value. * Significant at the 0.05 level. Independent variable: environmental uncertainty items total score.

The regression results show significantly positive coefficients for strategic pricing $(\beta=0.136, p=0.014)$ and balanced scorecard $(\beta=0.115, p=$ 0.033), while the use of the other SM A techniques is not influenced by the degree of PEU. Therefore, H1A is partially supported.

As goodness-of-fit measures, the proportion of correctly classified observations was calculated to evaluate the prediction ability of each logistic regression (Dong et al. 2011). This proportion ranges from 0.491 to 0.818 , with an average of 0.655 , indicating an acceptable performance of regression models.

As suggested by Simmonds (1982), product price changes may induce competitive reactions, which, in turn, may have large effects on the competitive positions of firms. These effects are not easy to predict accurately. To tackle this uncertainty, strategic pricing entails that data used in making pricing decisions, where product costs provide the point of departure, should be complemented with information on likely competitor reactions to changes in pricing policy. When price is viewed as a key element in strategic positioning, other factors that should be appraised in pricing decisions are the expected volume of sales, estimation of volume changes, projected market share, and other factors deriving from competitively oriented analysis. This outlook is ultimately manifested in strategic pricing (Guilding, Cravens, and Tayles 2000). The regression result shows 
that, in surveyed firms, strategic pricing is used in response to high PEU.

Balanced scorecard integrates short-term financial measures with a set of non-financial leading indicators of future, long-term performance, embracing four perspectives: financial, customer, internal business, and innovation and learning (Kaplan and Norton 1992). In this study, the result regarding the use of balanced scorecard is consistent with the view that when firms experience greater difficulty in predicting future events, they should use more management accounting information, with greater reliance on non-financial indicators for performance evaluation (Hoque 2004).

THE RELATIONSHIP BETWEEN PERCEIVED ENVIRONMENTAL UNCERTAINTY AND THE PERCEIVED USEFULNESS OF SMA TECHNIQUES

H1B was tested carrying out an ordinal logistic regression analysis for each sma technique. Ordinal logistic regression is based on the following model for an ordinal response variable with $j$ (more than two) categories and a single predictor (Agresti 2002):

$$
\operatorname{logit}[P(Y \leq j \mid X=x)]=\alpha+\beta X,
$$

where $j$ goes from 1 to the number of categories minus 1 . Here, $Y$ is the perceived usefulness of a certain SMA technique, which can assume values $(j)$ in the interval $1-7$, while $X$ is the explanatory variable calculated as the total score $(x)$ of the environmental uncertainty items. $\alpha$ is the constant of the model.

To support $\mathrm{H} 1 \mathrm{~B}$, the coefficient $\beta$ in the regression equation should be significantly positive. This would indicate that the probability that a certain SMA technique is perceived as more useful increases as PEU increases. Table 5 shows the results of ordinal regressions.

Significant and positive coefficients are found for the whole set of SMA technique considered, either at $5 \%$ or $1 \%$ significance level, indicating that for sampled firms perceived usefulness of sMA techniques would be an increasing function of PEU. These results provide support for Н1B.

Again, the proportion of correctly classified observations was computed to evaluate the prediction ability of each ordinal regression. This proportion ranges from 0.236 to 0.418 , with an average of 0.335 .

The regression results seem to suggest that, under conditions of high PEU, managers participating in strategic decision-making judge sMA techniques as more useful to collect and analyse information about en- 
TABLE 5 The Relationship between PEU and the Usefulness of sma Techniques

\begin{tabular}{lrrl}
\hline sM A techniques & $(1)$ & $(2)$ & $(3)$ \\
\hline Life cycle costing & 0.125 & 3.197 & $0.002^{\star *}$ \\
Quality costing & 0.088 & 2.421 & $0.019^{\star}$ \\
Target costing & 0.125 & 2.795 & $0.007^{\star *}$ \\
Value chain costing & 0.090 & 2.230 & $0.030^{\star}$ \\
Strategic pricing & 0.149 & 3.362 & $0.002^{\star *}$ \\
Brand valuation & 0.090 & 2.409 & $0.020^{*}$ \\
Competitor position monitoring & 0.133 & 2.905 & $0.006^{\star *}$ \\
Competitor cost assessment & 0.142 & 3.145 & $0.003^{\star *}$ \\
Competitor appraisal based on published financial state- & 0.107 & 2.788 & $0.008^{\star *}$ \\
ments & & & \\
Balanced scorecard & 0.162 & 3.669 & $0.001^{\star *}$ \\
\hline
\end{tabular}

Notes Column headings are as follows: (1) coefficient $(\beta),(2) z$ statistic, (3) p-value. * Significant at the 0.05 level. ${ }^{*}$ Significant at the 0.01 level. Independent variable: environmental uncertainty items total score.

vironmental or future concerns. This is consistent with the evidence, provided in previous studies, that the degree of perceived uncertainty is positively associated with the perceived usefulness of non-conventional management accounting information (Lal and Hassel 1998; Hoque 2005).

\section{Discussion and Conclusions}

The present study has sought to provide some insight on the relationship between PEU and SMA as specific broad scope and non-conventional management accounting system that aligns accounting with strategic management (Nixon and Burns 2012). Following a congruence approach (Gerdin and Greve 2004), it aims to contribute to the emerging body of literature on the antecedents of sMA adoption, addressing the suggestion for further research advanced in literature. In particular, the study adds knowledge by introducing PEU as a contextual variable in SMA framework and empirically testing the hypothesis that as PEU increases the use and perceived usefulness of SMA techniques increase to support strategic decisions. In doing so, the study extends the examination of innovative management practices within contemporary settings (Cadez and Guilding 2008).

Based on a sample of 55 large manufacturing firms in Italy, the regression-based statistical analysis performed to test the research hypotheses 
mainly shows: (a) that for large manufacturing firms included in the sample, PEU influences the use of specific sma techniques, such as strategic pricing and the balanced scorecard; (b) a positive association between PEU and the perceived usefulness of all SMA techniques included in the study. This suggests that when managers perceive situations of high environmental uncertainty they tend to regard SMA techniques as more useful but without increasing their adoption within organization. That is, based on the perceptions of the benefits that could derive from the greater use of such techniques, managers recognize the importance of a wide range of sMA techniques but their employment within firm is still limited. Indeed, the responses of CFOS are quite consistent with the view, advanced in prior literature, that non-conventional management accounting, such as SM A, can be useful to cope with environmental uncertainties and make more informed and accurate strategic decisions. However, it has to be noted that while PEU affects the perceived usefulness of all SM A techniques, firms seem to be selective in the use of sma techniques to tackle uncertainty in strategic decisions. This selective behaviour seems to be motivated by two different considerations. The first one is that the implementation of SMA techniques is extremely expensive, because it requires the adoption of an analytical and sophisticated information system (Inghirami 2017). The second one is that managers hardly understand the meaning of sMA concept. The prominent academic emphasis on the sMA concept and the paucity of empirical research make sma concept very difficult to understand. Furthermore, the usage rate of sma techniques is still limited, as reported by several empirical studies (LangfieldSmith 2008). Then, a paucity of knowledge and culture within firms concerning the importance of these non-conventional accounting techniques is empirically demonstrated. This suggests that deeper investigation is needed to understand the relationship between strategic decisions and the use of SMA as a package. Since strategic decisions differ, the design and use of sMA should be tailored to meet different contingency variables and, then, different information needs.

These conclusions are subject to the study's limitations. The main limitation regards the number of the sampled firms, which reflects its exploratory nature. Although these firms were randomly selected, to increase the validity of the results and to help determine the extent to which they can be generalized, the hypotheses need to be tested on a larger sample.

Another limit regards the operationalization of sm A techniques usage. 
The use of a dichotomous scale creates measurement error, as with this approach minor use in one firm equals extensive use in another firm. However, a purpose of this study, which is exploratory in nature, has been to identify firms that use or do not use a certain sma technique. Future development of the research would investigate the extent to which each sma technique is used.

Further, the study focus on a relationship between one independent variable (PEU) and one dependent variable (each sMA technique), whereas it may be 'essential to understand the interactions between multiple contingent and control factors in determining the effectiveness of control system design' (Otley 2016, 48). Additional research could be conducted to follow this recommendation, since it is likely that other factors, together with the degree of PEU, are influencing the adoption and use of SMA techniques.

\section{References}

Agresti, A. 2002. Categorical Data Analysis. 2nd ed. Hoboken: Wiley.

Agbejule, A. 2005. 'The Relationship between Management Accounting Systems and Perceived Environmental Uncertainty on Managerial Performance: A Research Note' Accounting and Business Research 35 (4): 295-305.

Bhimani, A. 2013. Strategic Finance: Achieving High Corporate Performance. London: Strategy Press.

Bhimani, A., and K. Langfield-Smith. 2007. 'Structure, Formality and the Importance of Financial and Non-Financial Information in Strategy Development and Implementation.' Management Accounting Research $18(1): 3-31$.

Bromwich, M. 1990. 'The Case for Strategic Management Accounting: The Role of Accounting Information for Strategy in Competitive Markets.' Accounting, Organizations and Society 15 (1-2): 27-46.

Brouthers, K. D., and F. A. Roozen. 1999. 'Is it Time to Start Thinking about Strategic Accounting?' Long Range Planning 32 (3): 311-22.

Cadez, S., and C. Guilding. 2007. 'Benchmarking the Incidence of Strategic Management Accounting in Slovenia.' Journal of Accounting and Organizational Change 3 (2): 126-46.

- 2008. 'An Exploratory Investigation of an Integrated Contingency Model of Strategic Management Accounting.' Accounting, Organizations and Society 33 (7-8): 836-63.

Carlsson-Wall, M., K. Kraus, and J. Lind. 2015. 'Strategic Management Accounting in Close Inter-Organisational Relationships.' Accounting and Business Research 45 (1): 27-54. 
Cescon, F. 2010. 'The Influence of А м т Firm Characteristics on Innovative Costing Techniques: A Contingency-Based Study.' In Economia aziendale e management: scritti in onore di Vittorio Coda, edited by G. Airoldi, G. Brunetti, G. Corbetta, and G. Invernizzi, 679-96. Milan: Egea.

Cescon, F., A. Costantini, and L. Grassetti. 2016. 'Strategic Perspective in Management Accounting: Field-Based Evidence.' In Il governo aziendale tra tradizione e innovazione. Vol. 4, Controllo di gestione, costiperformance, edited by L. Marchi, R. Lombardi, and L. Anselmi, 7-31. Milan: Franco Angeli.

Chenhall, R. H. 2003. 'Management Control Systems Design within its Organizational Context: Findings from Contingency-Based Research and Directions for the Future.' Accounting, Organizations and Society 28:127-68.

Chenhall, R. H., and K. Langfield-Smith. 1998. 'The Relationship between Strategic Priorities Management Techniques and Management Accounting: An Empirical Investigation Using a System Approach.' Accounting, Organizations and Society 23 (3): 243-64.

Chenhall, R. H., and D. Morris. 1986. 'The Impact of Structure, Environment, and Interdependence on the Perceived Usefulness of Management Accounting Systems.' The Accounting Review 61 (1): 16-35.

Chong, V. K., and K. M. Chong. 1997. 'Strategic Choices, Environmental Uncertainty and sBU Performance: A Note on the Intervening Role of Management Accounting Systems.' Accounting and Business Research 27 (4): 268-76.

Cinquini, L., and A. Tenucci. 2010. 'Strategic Management Accounting and Business Strategy: A Loose Coupling?' Journal of Accounting and Organizational Change 6 (2): 228-59.

Coad, A. 1996. 'Smart Work and Hard Work: Expecting a Learning Orientation in Strategic Management Accounting.' Management Accounting Research 7 (4): 387-408.

Cronbach, L. J. 1951. 'Coefficient Alpha and the Internal Structure of Tests.' Psychometrika 16:297-334.

Dong, J.-J., Y.-H. Tung, C.-C. Chen, J.-J. Liao, and Y.-W. Pan. 2011. 'Logistic Regression Model for Predicting the Failure Probability of a Landslide Dam.' Engineering Geology 117:52-61.

Fisher, J. 1995. 'Contingency-Based Research on Management Control Systems: Categorization by Level of Complexity. Journal of Accounting Literature 14:24-53.

Gerdin, J., and J. Greve. 2004. 'Forms of Contingency Fit in Management Accounting Research: A Critical Review. Accounting, Organizations and Society 29 (3-4): 303-26. 
Gordon, L. A., and V. K. Narayanan. 1984. 'Management Accounting Systems, Perceived Environmental Uncertainty and Organization Structure: An Empirical Investigation.' Accounting, Organizations and Society 9 (1): 33-47.

Guilding, C., K. S. Cravens, and M. Tayles. 200o. 'An International Comparison of Strategic Management Accounting Practices.' Management Accounting Research 11 (1): 113-35.

Guilding, C., and L. McManus. 2002. 'The Incidence, Perceived Merit and Antecedents of Customer Accounting: An Exploratory Note.' Accounting, Organizations and Society 27:45-59.

Gul, F. A. 1991. 'The Effects of Management Accounting Systems and Environmental Uncertainty on Small Business Managers' Performance.' Accounting and Business Research 22:57-61.

Gul, F. A., and Y. M. Chia. 1994. 'The Effects of Management Accounting Systems, Perceived Environmental Uncertainty and Decentralization on Managerial Performance: A Test of Three-Way Interaction.' Accounting, Organizations and Society 19 (4-5): 413-26.

Hair, J. F., W. C. Black, B. J. Babin, and R. E. Anderson. 2010. Multivariate Data Analysis. 7th ed. Upper Saddle River, NJ: Pearson Prentice Hall.

Hoque, Z. 2004. 'A Contingency Model of the Association between Strategy, Environmental Uncertainty and Performance Measurement: Impact on Organizational Performance.' International Business Review 13:485-502.

—. 'Linking Environmental Uncertainty to Non-Financial Performance Measures and Performance: A Research Note.' The British Accounting Review 37 (4): 471-81.

Inghirami, I. E. 2017. 'Building Effective sm A Systems Taking Advantage of Information Technology.' In Reshaping Accounting and Management Control Systems: New Opportunities from Business Information Systems, edited by K. Corsi, N. G. Castellano, R. Lamboglia, and D. Mancini, 167-81. Cham: Springer.

Invernizzi, G. 2005. 'Lo Strategic Management Accounting.' In Strategic Management Accounting: una ricerca sui sistemi di supporto alla gestione strategica, edited by G. Invernizzi, 7-18. Milan: Egea.

Kalkhouran, A. A. N., S. Z. A. Rasid, S. Sofian, and B. H. N. Nedaei. 2015. 'A Conceptual Framework for Assessing the Use of Strategic Management Accounting in Small and Medium Enterprises.' Global Business and Organizational Excellence 35 (1): 45-54.

Kaplan, R. S., and D. P. Norton. 1992. 'The Balanced Scorecard: Measures That Drive Performance.' Harvard Business Review 70 (1): 71-9.

Lal, M., and L. Hassel. 1998. 'The Joint Impact of Environmental Uncertainty and Tolerance of Ambiguity on Top Managers' Perceptions of 
the Usefulness of Non-Conventional Management Accounting Information.' Scandinavian Journal of Management 14 (3): 259-71.

Lord, B. R. 1996. 'Strategic Management Accounting: The Emperor's New Clothes?' Management Accounting Research 7 (3): 347-66.

- 2007. 'Strategic Management Accounting.' In Issues in Management Accounting, edited by T. Hopper, D. Northcott and R. Scapens, 135-53. Harlow: FT Prentice Hall.

Langfield-Smith, K. 2008. 'Strategic Management Accounting: How Far Have We Come in 25 Years?' Accounting, Auditing and Accountability Journal 21 (2): 204-28.

Milliken, F. J. 1987. 'Three Types of Perceived Uncertainty about the Environment: State, Effect, and Response Uncertainty. The Academy of Management Review 12 (1): 133-43.

Nixon, B., and J. Burns. 2012. 'The Paradox of Strategic Management Accounting.' Management Accounting Research 23 (4): 229-44.

Noordin, R., Y. Zainuddin, R. Mail, and N. K. Sariman. 2015. 'Performance Outcomes of Strategic Management Accounting Information Usage in Malaysia: Insights from Electrical and Electronics Companies.' Procedia Economics and Finance 31:13-25.

Noordin, R., Y. Zainuddin, and M. Tayles. 2009. 'Strategic Management Accounting Information Elements: Malaysian Evidence.' Asia-Pacific Management Accounting Journal 4 (1): 17-34.

Noreen, E., P. C. Brewer, and R. H. Garrison. 2011. Managerial Accounting for Managers. 2nd ed. New York: McGraw-Hill/Irwin.

Otley, D. 2016. 'The Contingency Theory of Management Accounting and Control: 1980-2014.' Management Accounting Research 31:45-62.

Pitcher, G. S. 2015. Management Accounting in Support of the Strategic Management Process. London: Chartered Institute of Management Accountants.

Robinson, J. P., P. R. Shaver, and L. S. Wrightsman. 1991. 'Criteria for scale selection and Evaluation.' In Measures of Personality and Social Psychological Attitudes, edited by J. P. Robinson, P. R. Shaver, and L. S. Wrightsman, 1-16. San Diego, CA: Academic Press.

Roslender, R., and S. J. Hart. 2003. 'In Search of Strategic Management Accounting: Theoretical and Field Study Perspectives.' Management Accounting Research 14 (3): 255-79.

Shank, J. K., and V. Govindarajan. 1993. Strategic Cost Management: The New Tool for Competitive Advantage. New York: The Free Press.

Simmonds, K. 1981. 'Strategic Management Accounting.' Management Accounting 59 (4): 26-9.

1982. 'Strategic Management Accounting for Pricing: A Case Example.' Accounting and Business Research 12 (47): 206-14. 
Sullivan, G. M., and A. R. Artino. 2013. 'Analyzing and Interpreting Data from Likert-Type Scales.' Journal of Graduate Medical Education 5 (4): 541-42.

Tenucci, A., L. Cinquini, and R. Giannetti. 2010. 'Implementation and Perceived Usefulness of Advanced Management Accounting Techniques: A Survey on Italian Firms.' In Contemporary Research in Cost and Management Accounting Practices: The 21st Century Perspective, edited by N. C. Shil and A. K. Pramanik, 109-27. Miami: North American Business Press.

Tillmann, G., and A. Goddard. 2008. 'Strategic Management Accounting and Sense-Making in a Multinational Company.' Management Accounting Research 19 (1): 80-102.

Tymon, W. G., D. E. Stout, and K. N. Shaw. 1998. 'Critical Analysis and Recommendations Regarding the role of Perceived Environmental Uncertainty in Behavioral Accounting Research.' Behavioral Research in Accounting 10:23-46.

Ward, K. 1992. Strategic Management Accounting. Oxford: ButterworthHeinemann.

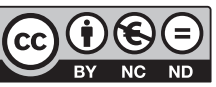

This paper is published under the terms of the Attribution-

NonCommercial-NoDerivatives 4.o International (CC B Y-NC-ND 4.0)

License (http://creativecommons.org/licenses/by-nc-nd/4.o/). 